\title{
Home/Work: The Roles of Education, Literacy, and Learning in the Networks and Mobility of Professional Women Migrant Carers in Cumbria \\ Sondra Cuban
}

\begin{abstract}
This study focuses on a group of highly skilled female migrants who were carers to the elderly, and the roles of education, literacy, and learning in their social networks and mobility in Cumbria, England. Over a year period, interviews were conducted with care training specialists, carers, clients, and employers across England, including Cumbria, in conjunction with literature reviews and observations to develop themes about this phenomenon. Findings revealed that there were many barriers to the carers' adjustment and advancement in a new area of settlement, and that these obstacles were complex and invisible to the care sector establishment; while the women's migration took place over physical borders, there were also hidden socio-economic, cultural, policy, and "paper walls" (Brinkmann, 2006) that prevented their access to professional jobs, further and higher education, and formal associations. This case study casts many questions about the geographies of skilled migrant women and their roles in transforming the global care sector as well as their local communities through their educational capital.
\end{abstract}

\section{INTRODUCTION}

This exploratory study is about the ways education, literacy, and learning operated within the social networks and mobility patterns of professional migrant women who were carers to the elderly in a rural northwest region of England--Cumbria. Using care and migration literature, I describe the situations of women migrants in the care sector, and the development of the care sector in England, ${ }^{1}$ as part of a global industry. Then, I use the literature, and my findings, to outline Cumbria's socio-economic position within England, especially the northern region. Next, I describe my methodology, and end with themes that I developed from both the literature and my study. The study attempts to connect three distinctive concepts that are rarely brought together in the study of migrant carers: home, work, and education. In this case, 'Home/work,' (the title of this article), encompasses five layers of meaning: 1) the intersection of professional women migrants' home and community lives with their work lives and relations; 2) gendered and migrantdependent care in a post-welfare society; 3) the educational capital women bring and develop, as they migrate from their home countries to work in Cumbria, England; 4) the informal educational and learning strategies (homework) that the women used, and finally, 5) the reflexive account of an economic migrant woman researcher positioned within the 'knowledge-based economy' studying migrant women in the secondary service sector (Smith, 2005).

\footnotetext{
${ }^{1}$ The study takes place in Cumbria, which is in the northwest region of England, where carers, employees and clients were interviewed and observed. Additionally, interviews with care specialists and literature reviews were made throughout England. Therefore, Cumbria serves as a case study of the care sector in England, as well as the global care phenomenon.
} 


\section{Intersectional Theoretical Framework}

Feminist researchers (Silvey 2005, Ackers 2004, Anderson 2006, Raghurum \& Kofman 2004, Duffy 2007, Kofman et al 2000) have rightly pointed out that gender is neglected in labour migration studies, even though this population is predominantly female. They have called for intersectional approaches, factoring interlocking systems (gender, race, and class), as they are tied to both migration and reproductive labour. Furthermore, Mahler \& Pessar (2006) discuss women migrants' mobilities, focusing on intersections of geographical and social locations, power, and ideoscapes (symbols). The conventional definition of mobility (Silvey 2004) is legalistic and rationalistic, with women's migration configured as a series of discrete events, tied to men's jobs, rather than a process that incorporates socio-psychological dynamics (migrating to escape workplace discrimination, provide for children, or for autonomy), legislation (skills point systems), and political aspects (crossing state boundaries and citizenship status) as well as economic strains (structural adjustment programmes, SAP). These researchers focus on the complex reasons for women's migration, suggesting that it is not simply push and pull factors (Ackers, 2004). Women's labour migration is tied to larger structures of power-capitalism, patriarchy, and the racial division of labour but also micro levels, like, the household as a workspace for women and work/life balance (Silvey 2007, Datta et al 2006). This study concurs, that migrant women have diverse migration paths and trajectories, with numerous factors mediating their experiences.

The interactionist framework is different from instrumentalist perspectives that highlight migration as a common good; studies, for example, might measure migrants' mobility in terms of their human capital and their economic contributions to receiving countries. Businesses share this perspective since a transient migrant labor force allows for transnational control (Pai, 2004). Similarly, government policies support migration, only in so far as migrants benefit the economy. A reactionary, ambivalent response takes over with worries that migrants could rely on public funds, draining an already tight supply. Stricter controls have been incurred on migrants and refugees, affecting their access to public services and encouraging their circular migration rather than settlement; English For Speakers of Other Languages (ESOL) programmes, formally free to European Union (EU) citizens, for example, started to charge fees in 2007 (see, The Guardian, July 20, 2007).

\section{Rationale}

What are absent from both sets of literature are the trajectories of skilled migrant women workers and the educational capital they contribute to the globalised service sector. Little data on this group exists (Kofman 2000, Raghuram \& Kofman 2004). While research shows that it is skilled women who are often the ones who migrate because they can pay the fees and have skills that are in demand (Cox, 2006) and subsequently, may be easier to integrate by the host country (LSC 2006), the primary focus, at least in the media, is on unskilled workers, as the 'migrant imaginary.' Professional women's educational qualifications, academic resources, and sophisticated language and literacy practices (educational capital) are either not factored into the labour equation at all, or, are viewed deficiently (their qualifications are substandard). Because of this reductive focus, questions about why so many professional women are leaving the knowledge-based 
economy to work in the secondary service sector and becoming deskilled, in their "race to the bottom" are not asked. The literature also does not address regional differences, and how migrants adjust to rural areas, or how their experiences, identities, and networks may be different than migrants in London where there are established social services and support systems as well as places to work. Global cities are the focus (Kofman 2000). Thirdly, the literature focuses on migrants' "integration" into the labour market, suggesting that assimilation is a positive outcome. This normative outlook reflects larger policy discourses on migrant labour; the social integration/cohesion discourse does not factor in the ways that skilled migrants are 'upscaling' or professionalizing the labour force, and the central roles they play in transforming social welfare, as well as their symbolic resources. They are strong actors without being credited as such, because, of their contradictory situation- "well-educated, low-priced labour" (Momsen 1999, p.10). The fact that an increasing amount of skilled women are entering the care sector workforce, yet with little knowledge about the ways they transform it, as well as their local communities, with their educational capital, needs to be better understood.

\section{Migrant Women and Care In England}

Care is one of the fastest growing sectors in England today (Cox 2006). In just ten years, the care sector has grown exponentially to match England's burgeoning ageing population. The care sector is predominantly female in addition to having one of the highest migrant labour populations (Raghuram \& Kofman 2004). With its stigmatized image (as 'dirty, disposable, and degrading' work) low pay, and the widespread rejection of caring jobs by British-born youth, combined with pressures to perform many new and different functions, it is widely perceived as a vocation at the bottom of the job ladder, and only for those who are desperate. Currently, there are over 200,000 women migrants who work as au pairs (Cox, 2006), a number of whom are university educated. Although they are called cultural exchange workers, and come on tourist or student visas, they are now part of a migratory domestic service system due to a relaxation of labour and migration laws and government subsidies for the middle-class (to hire students) (Cox 2006, Pai 2004). Similarly, for the elderly, skilled migrant women make up a good part of the hundreds of thousands of care workers in private, residential, and nursing homes. They may also come to the UK on student visas or have work permits. It is, perhaps, no coincidence that female skilled migrants are available to work in a growing feminized industry during a period in which there has been a drastic liberalization of care (Cox 2006). Currently, the dominant delivery system for the elderly is individualised, and they now purchase their own care services. They almost always choose the cheapest option (Milligan 2001).

Although the care economy becomes the 'shock absorber' of the process of shifting from citizen welfare to the global market, it is less so for the workers themselves, who provide the service (Porter \& Judd 2005), and it offers few social protections, and many risks (legal, financial, emotional, socio-cultural). Historically, England has had a history of servants and maids but migrants have moved into this field in a large-scale way, and are specifically sought for these positions (Cox 2006). Many factors in high-income countries combine to account for the demand: An ageing population (especially those over 85), women's career structures which seldom allow for breaks to care, increasingly long hours 
at work, deregulation of care, and drops in health care coverage. Women family members have traditionally provided care for free or for long hours, with this legacy passed on to migrant workers (Cox 2006).

Migrant women contribute to the development of high-income families, as well as their own families' quality of life, through remittances. When women remit to their families, they also maintain their support roles, as mothers, wives/partners, sisters, daughters, helping them to survive from a distance (Parrenas 2002). While developing countries rely on these remittances they also experience both 'brain drain' and 'care drain' when these women migrate, and government policy makers in receiving countries as well as business proponents promote these workers as young and transient, unlikely to 'drain' the National Health Service (NHS) or the schools. Such policymakers ignore how migrants have contributed greatly to the transition from state-run institutions for the care of the elderly to privately subsidized and market-driven care.

Little is known about how migrant women create, what Sassen (2002) calls, 'survivor circuits' to cope with these globalization trends. A feminist transnational perspective (Naples 2004) focuses on the important ways that women migrants contribute to their local and global communities, and their 'transnational literacy' (Spivak 1992) as they move around with their educational capital, negotiating state boundaries and private and public spheres (Mohanty 1997). They enact a participatory and civic citizenship that is not often recognized as such, because it is smaller, by women, and, not in traditional places (Stromquist 2006).

\section{The Care Sector Becomes Professionalized}

Care work has not often been recognized as "real" work and researchers have attempted to move it from its familial and emotional connotations in the informal economy ("care as a labour of love') to situate it within the productive sphere of the labour market (Twigg 2000). While there has been considerable debate amongst feminists as to whether the home is a workplace for women in the informal economy, less is said about paid care. Twigg (2000) has discussed paid care along multiple dimensions: Emotion, labour, culture, and body work. Studies of nursing (Brilowski \& Wendler 2005), are useful in that they have focused on the occupational concept of care, acknowledging that it has changed from a more humanized to a market-based service focused on cost-savings and efficiency. With greater modernization of the health sector, caring has altered and been linked to increasing formal education, literacy, and technologies (Browne \& Kirpal 2005). As nurses are upgraded to diagnosing, the care workers, often, take up their former work, yet with more technical emphasis. The valuation of care work, however, keeps changing. Browne and Kirpal (2003) show that there is a inexhaustible list of skills and behaviors that cannot be accounted for in health care practice, especially as the field attempts to integrate expressive (emotion) care with instrumentalist forms of care (the competency to do paperwork). Furthermore, national vocational qualifications (NVQs) are now required by The Care Standards Act of 2000 so that carers comply with health and safety measures and this regulation has put pressures on employers and employees to supply appropriate vocational qualifications at a level 2 (Weston 2006). This regulation has had many different kinds of effects. Recent studies, for example, point to stress as a 
major issue amongst women carers now (Weston 2006). This trend also makes training big business.

Training has most often focused on functional tasks and is competency-based (how-to-do it). Jackson (1991) finds that these types of trainings were meant for low-status women's fields and because they would not be resisted by women workers. But more than that, the training advances the employers' needs, as it is, 'education on the cheap' (p. 366). Basic skills are embedded into training courses for carers, because of their perceived lack of formal education and literacy skills. Yet, there is no solid evidence about these training benefits for workers and ethnographic workplace training studies in the England are nonexistent (Ananiadiou, Jenkins, \& Wolf 2004, Roberts et al 2005). Most promotions for training do not account for the barriers inherent in the workplace which cause low motivation, not to mention, low attendance and absences; unpredictable schedules, no pay to train, high turnover, and coverage problems (Weston 2006, Simon et al 2002) are the norm. Finally, the curriculum, does not factor professional migrants' expertise, their aspirations, and movement between jobs and unfamiliar cultures, as well as their uses of new media and texts.

\section{CONTEXT OF CUMBRIA, ENGLAND: SAME LANDSCAPE NEW ECONOMY}

Although there is a history of internal migration to the north of England, where Cumbria is located, the region did not exhibit large-scale service sector needs until recently and there is now demand for migrant labour from the European Union and other countries to work in its new economy (Simon \& Pemberton, 2006). Much of the literature focuses on how migrants are regenerating these towns economically, but very little is said about the problems they face. For skilled and unskilled labour groups there are few social support services in rural northern towns, and they face the general problems of rural communities --- poor health, education services, isolation, and a downward cycle of poverty (Ellery 2006). Little attention has focused on skilled migrants, and their movement into areas, such as Cumbria, where there is no history of mass migration settlement.

Cumbria, situated between the Irish sea and the Pennine Hills is the second largest county in England, and covers a sizeable, sparse area that contains considerable geographic diversity. Socioeconomic circumstances have changed the economy for its 500,000 residents (Bennison 2007), and global capitalism has hit Cumbria hard, creating distinct social classes, and pockets of poverty next to wealth. Rural communities have been forced to move from agriculture (in the north and east of Cumbria), and manufacturing (in the west of Cumbria), after the decline of shipping to service. The southern coastal areas like Barrow and Worthington are undergoing drastic transitions from sea-related manufacturing with large deprivation. In the northern and eastern regions of Cumbria, historically agricultural, farming has declined leaving a significant vacuum for service because like many rural areas, Cumbria has a large elderly population, one that is in illhealth and fairly isolated (Bennison 2007 Roe \& Cuerdon 2004). Due to the growth of the service sector, skills surveys have flagged Cumbria as lower than average, and until 2007, there were no higher education institutions. Yet the County as a whole does not have high crime rates and it has an older retired community who bring in income, entrepreneurs and family businesses, as well as low birth rates, strict housing development, and many 
people who are commuters from Lancashire. These issues mitigate other economic indicators (Roe \& Cuerdon 2004).

Known for its stark beauty - the Lake District, which has been described in detail by renowned authors, attracts many tourists and the elderly who want to retire making it a prime place for health care and hospitality. But without service workers, Cumbria's economy would shrink considerably. Therefore, active recruitment of migrant women has helped solve the problem, advancing these sectors even more. In Cumbria, many Polish people work in bars, restaurants, in cleaning, and in care homes, sending money home, and saving it for their education, and future moves. Polish newspapers, stores, and churches are often used for information sharing and gathering places. Yet, reports have revealed overcrowded housing, safety hazards for workers, and little access to benefits in the north (Ellery, 2006). One example from this study illuminates these issues. Elsa, an insurance broker from Poland and in her 20s, first visited Cumbria to see her friend who was living in an overcrowded house. Elsa paid $£ 55$ a week for her bed, which was on one side of the main room. Rather than complain, she left, only to become homeless, and was helped by a Polish man she met on the street. Likewise, in other parts of Cumbria, like Barrow-in-Furness, there are Filipina care workers and nurses who struggle with racial prejudices, few established support systems, unpredictable work permit and residency regulations (Winkleman-Gleed 2005). Three Filipinas explained that many carers had few support services to adjust. They noted that residents, at least initially, often confused them with the Chinese, that there were no language schools for their children, and they worried about their them losing Tagalog, and speaking Taglish.

\section{METHODS}

The study situates the perspectives of women who have settled in areas where there is scarce documentation about migration (Cumbria). Macro-data (from the literature review) is used to build hypotheses (or themes) about a new, transnational phenomenon, highlighting the experiences of these women (Smith 2005, Strauss \& Corbin 1990, Naples 2004)

\section{Data Collection}

From April 2006 to November 2006, phone and face-to-face interviews were conducted across England, with care training providers, care organization staff, and literacy agency staff who were involved in the care sector. During this time, contacts in Cumbria were obtained and I focused my research in this region since the literature showed that it had both a rising ageing and migrant population, as well as care home expansion. Also, policymakers in the field of care said there was little research on this phenomenon in this region. Five care homes in Cumbria were identified in: Carlisle (the northern region), Barrow-in-Furness (western region), Kendal and Carnforth (southern region) and Windermere and Ambleside (central region). The care homes were of different sizes and types (residential, nursing, sheltered, domiciliary), and were purposively sampled. Additional data was collected on nine migrant women carers from January to March 2007, through weekly and bi-monthly visits to their workplaces and training sites. The visits familiarized me with all of the participants, including carers (both migrant and British-born), clients, trainers, and employers. Finally, one carer became an informant to 
me, enabling me to ask her additional questions that other carers only hinted at in their interviews.

\section{The Carers}

The women were sampled firstly because they were women, migrants and carers. After learning that most of these carers were highly skilled, I continued to sample based on professional qualifications and education levels and to get an ethnic balance. The major source of data comes from interviews, which I conducted with thirty professional migrant women from November 2006-June 2007. Each woman was interviewed for an hour or more, focusing on her reasons for migrating, the steps she took to migrate, her work history, and about her educational qualifications. I also asked her about the networks she formed, the supports she exchanged, her use of community resources, and lastly, about her experiences of living and working as carers in Cumbria, as well as her aspirations.

The women came from working-class and middle-class backgrounds in Romania, Thailand, India, the Philippines and Poland, with the last three countries most represented. Most of the carers were within a year to two years of arriving in England and were in their first jobs. Those who had spent more than a year in England often had other jobs before they arrived to their company, and it was usually in hotels, restaurants, or factories, or they had recently graduated from university. The women ranged in age from their 20s to their 50s. Most of the Polish women were single without children while Indian women tended to be either engaged or married, with a few having children. Almost all of the Filipinas were married, with husbands who also worked abroad, and most of them had children, who were being taken care of by their parents. A few spouses joined the women, but most families did not come over to England to live. However, many of the women's relatives, especially the Filipinas' lived in other countries and a couple of the carers' mothers from Poland, also worked abroad as carers.

Many of the women came from small cities and towns, and a large proportion of them were recruited by agencies through the internet, newspapers, and flyers, and some of them had friends who referred them to the agencies or directly recruited them. While a few of the Filipinas had worked abroad (in Israel or in Saudia Arabia), most of the women had not, and, saw England as their first transnational stop, in their moves across the world. Many women, especially registered nurses, aimed to go to the U.S. to work because they heard there were more jobs there or they had family members who lived there. Australia was another destination. All of the women, except one, had graduated from university and all of them could be considered professionals in their countries (nurses, insurance brokers, teachers, physical therapists). Yet their educational qualifications were not recognized in England ${ }^{2}$.

\footnotetext{
${ }^{2}$ One of the nurses, when she first came over to England, was told by her employer that she was in 'training' to be a nurse, but she did not receive a nurse's salary, and it was unclear to bother her and myself whether or not she was working as a nurse or carer, during this period. Another woman carer eventually got a job as a nurse outside of Cumbria during the period of the study.
} 
Almost all of the women worked over 40 hours a week at their jobs, and only a few worked at their set contract hours, with many working around 60 hours a week and some close to 70. It was not uncommon for carers, especially senior carers, to work nearly 100 hours over a ten-day period, and 10-12 hour shifts. They often asked for more hours due to the fact that few care homes paid overtime for working nightshifts and pay hovered around $£ 6 /$ hour. Working these hours, they could afford to pay for basic necessities and send money home. Their costs of living were high in comparison to their wages. All of them lived in apartments and houses and paid an average of $£ 240$ a month for a bed in a room with 2 people, in addition to many other amenities, which were not included in their rents. Most of the women were in debt in some way, either to their families for agency and moving fees, and/or to their employers (for car loans). These debts appeared to keep them tied to their jobs, all of which were contracted (yearly and then every 2 or 5 years). For the women with families, it was expected that they send money to them, and after their debts were paid locally, all mothers, sent most of their monthly income. The money was used for health, school, and basic necessities, which had recently risen (probably due to SAP).

\section{Employers}

I got to know three of the five employers fairly well, with one becoming an informant. Five of the employers were each given interviews, with three participating in follow-up interviews and focus groups. All of them were care home managers, British-born, mostly former nurses, and all, except one were women. The employers discussed the stresses of their jobs (especially increasing amounts of auditing and regulations), the need for constant training of their employees to meet changing regulatory rules, and the advantages and disadvantages of employing migrants. Advantages were mainly that they filled an important need as they had high vacancy rates and were frequently short-staffed. Other advantages were that migrants could recruit for them, which allowed them to hire more staff. The employers felt that these carers were able to work long hours, and were hard workers, the clients liked them, they were easy to train, and agreeable to working with their British-born colleagues. Disadvantages were problems around miscommunication due to speaking a second language, accents between elderly Cumbrians and the carers, and cultural expressions, and idioms were sometimes sources of confusion. Employers felt that some migrant staff misunderstood instructions that they were initially given, but that these could be explained and rectified. Most employers saw these communication problems as resolvable. But other problems were more complex and out of their immediate control, such as the housing market, transportation, and cost of petrol. These factors disabled the carers from being settled and getting their basic needs met, and put employers in delicate positions. Two employers discussed how some ethnic groups 'stick together' which they saw as problematic. All of the employers were sympathetic with the fact that a number of the carers were qualified nurses, and two employers gave them opportunities and time off to take adaptation courses. One employer paid for two staff members to take English courses at a Further Education (FE) college while another one rotated nurses, albeit haphazardly, through adaptation courses. It was clear that the employers had many factors to balance in hiring migrant staff, and most seemed to take the responsibility seriously. Still, it was clear that their allegiances were with the owners of the companies, and their bottom-line agenda to make profits. 


\section{Limitations of the Study}

There were several limitations. Firstly, my initial entry was through the employers, rather than through the women's networks, which initially impacted the ways the migrant carers perceived me. To reduce the perception that I was allied with the employers, and would reveal information to them, I introduced sensitive subjects in a natural way, like speaking about my own experiences at work as a 'migrant' in England and they were doubly reassured that everything they revealed to me would be confidential and that their identities would be disguised in reports, articles, and presentations. Secondly, the interview period was less than a year, and the women were newly arrived. Therefore, I, thereby limiting the scope and depth of the study did, not see changes, as well as other parts of their lives. Thirdly, it was a convenient sample. Lastly, all but one, of the interviews were taped, but due to time and resources, only 16 were transcribed. These transcriptions, however, represented many of the issues of the thirty women.

\section{Analysis}

A short case study of each woman was made, using the interview data, transcripts, and field notes about the workplace, the employer's perceptions and observations. Then, a grid of the women's socio-demographic traits and their literacy/language/education experiences was developed. This matrix allowed me to compare the women's issues, and establish a wide-ranging list of general codes that represented the phenomenon. Using these codes, I carefully read through all of the case studies again to confirm them, and condensed them into a shorter list. I also searched for key metaphors, phrases, images, and statements they made, as well as silences and pauses about sensitive issues. A research assistant and I used this information to create a list of multifaceted codes. The transcripts were coded by the assistant through AtlasTi, and I also coded some of the transcripts separately for reliability purposes. Anecdotes compiled within each code were examined for patterns and to generate a list of general categories. These categories were then cross-compared to check their validity across other case studies, and to generate themes about the roles of education, learning, and literacy in the networks and mobility patterns of the women. The themes are presented below.

\section{THEMES}

As the migrant women moved to and between their new homes, communities, and workplaces, they engaged episodically in education, used literacies to negotiate workplace cultures, and they formed innovative networks to help them adjust. But they had little upward mobility or opportunities to advance. There were many forces creating these circumstances. These themes are: 1) Balancing the $4^{\text {th }}$ shift of paperwork and person-centred care, 2) survivor circuits of the north, and 3) The myth of English and education escalators for career advancement

1) The $4^{\text {th }}$ shift- Professional migrant women can balance the paperwork with person-centered approaches to modernized care.

The amount of paperwork and time to complete it in the modernized care setting was dubbed, "the fourth shift," because it was extra work that was not accounted for on the 
job and it reinforced their subjugation. This metaphor builds on the work of Hochschild (2002) who refers to the $2^{\text {nd }}$ shift, where women work for pay during the day and then come home only to do unpaid work--cleaning, caring and emotional labour. The third shift (Bolton, 2000) represents women having to manage increasing educational and career demands, in order to advance. Following from these ideas, my research and the literature indicate that mature British-born carers were leaving the care sector due to the stress of managing education $\left(3^{\text {rd }}\right.$ shift) and paperwork ( $4^{\text {th }}$ shift) (Rainbird, Senker, \& Evans 2003, Brown \& Kirpal 2003). Once they leave, vacancies open up to migrants who have little choice but to comply with these demands. With their higher levels of formal education, transferable generic skills, (LSC 2006, Green, Owen, \& Wilson 2006) and participation in skilled migration chains, these carers are more likely than the Britishborn carers (who came to care because it did not require this work) to pass national literacy tests and NVQ exams with little or no training and recruit family and friends who do the same (Johnston et al. 2006, Sassen 1998). Recruiting these workers, then, is an economical strategy for employers because they do not have to provide training, which has rarely been available to British-born carers, anyway, and, they could secure a nonthreatening workforce who could work overtime, under pressured conditions, without questioning British labour laws and their rights as workers.

The employers in the study did not necessarily recruit professional migrant care workers because of their expertise with paperwork, but because they were a cost-efficient solution to staff shortages. However, when considering training, they viewed migrant workers' advanced English skill levels and previous education and training as a value-added incentive, since they were under pressure to have staff achieve quotas for the state mandated NVQs. It was clear from the interviews that the carers' professional expertise and skills enabled them to handle new and routine paperwork and they understood the techniques of technical writing. This was important since it was clear that there was a paperwork explosion with many duties needing to be recorded in logs (dietary charts, toilet charts, log sheets), plus, more training, auditing, and the invasion of new tests. These carers knew they could write in a form of shorthand and found writing in the requisite forms to be easy busywork, even noting that their British colleagues found this task difficult, as they often requested spelling assistance from them, and were amused at their inappropriate note-taking. While the paperwork was easy for them to deal with, it created extra work for them and bound them to a type of care that was labour-intensive because of its task specificity.

At the same time, the carers also understood the importance of person-centred care and the interpersonal skills that were needed to make clients feel comfortable. So, they sought to improve their knowledge of Cumbrian humour, of, chatting, being polite in a way British elders would appreciate, and smiled continuously so as to provide succor, when words weren't possible. Much of the communication they had with clients read like a script, with the same subjects repeated daily, as if it were a ritual ('the weather is bad'). One carer explained the importance of easing the client through body language and she smiled continuously despite the fact that she said she was, 'crying inside' (because she missed her children in the Philippines). Not only did these carers hold this knowledge and skills, but also they used them even when they were not solicited. One client knew the 
'foreign' staff had professional expertise, which reassured her she was getting a good deal. The carers also felt that their professional training and qualifications impacted their ability to offer excellent care to the clients, even when their supervisors, doctors, and nurses did not recognize it.

As part of being viewed as a competent professional, and because they felt they were outsiders and needed to be compliant with regulations, they rarely complained about their situations, even when they were intolerable. They did not seek out unions or any kind of formal advocacy. A couple of the women experienced gender and racial discrimination on the job, with clients yelling racial epithets, offensive names or treating them like slaves; one client actually called the carers 'slaves' while another one told her carers to 'fuck off' when they walked in the door and greeted her. Many of the carers would either report these difficulties and hope the management would rectify it, or they went out of their way to not inform the employers of their hardships even when it was the employers' responsibility to remedy the situation. They felt they had to resolve the problem alone and withstand it by being understanding about their clients' condition. This unspoken individualistic expectation was upheld in the management discourse of professionalism. Observations of trainings and analysis of training manuals focused heavily on carers handling their own problems, and at best, recording complaints. Abuse workshops and curriculum, for example, focused on how carers should not abuse patients, and if clients abused them, it could be managed. Yet little was done for the carers when patients, especially those who were considered to be mentally ill, hit them or verbally harassed them. A number of them felt terrible and hopeless after these incidents. In addition, since many of the women had experienced gender and racial discrimination in previous jobs where there were no protections either, they were not used to lodging complaints, protesting their conditions, or seeing anything positive transpire from official grievances.

The paperwork that women really needed help with (but got little of ) was the ubiquitous administrative and legal paperwork from recruitment agencies during the pre-migration stage. Often the women did not know what fees they paid for, and the agency was rarely clear about the costs, even when they were exorbitant ( $£ 3000$ for example). They also gave few timelines for when their paperwork would be finished, and in numerous cases, cash was asked for and no receipts were given, with demands to 'trust us.' Agencies would often blame another organization for delays, informing applicants that their case was legally difficult, using this to incur more fees. Agencies typically gave the women very little, except a foot in the door, a promise of a professional position once they finished their contracts as carers, and an initial employer contact. This seemed to be enough to convince family members to loan them money. The agency would hire several carers at once, identify care homes to send them to, and arrange for someone to meet them and house them for a few days before they went to their requisite homes. One woman, upon reaching England, was abandoned by her agency, and homeless. She received help by consulting a family friend in London. Most of the women felt that the agencies had overcharged them, and it appeared that a couple of them were under investigation. 
2) The women created survival circuits to help them acculturate, learn, and exchange information that was linked to global supply and demand for care.

The 'survival circuits' of migrants (Sassen, 1998) serve many functions, and are not composed of their personal networks strictly for adjustment to a new culture. They are indicative of what is referred to in the literature as, 'global care chains' (Parrenas 2002). This concept, although not solidly defined, refers to the ways that women, often from developing countries, get drawn into paid and unpaid care work in industrialized countries, of caring for children or the elderly, through each other, as well as through care sponsors (like recruiters), and the ways their networks form around their care, including supporting carers for their own children abroad; some women for example, in this study, recruited one another through word-of-mouth, supplying the agencies with credentials, and employers with employees, and a number of them had carers for their own children abroad. These survivor circuits could also become channels for exchanging information about education, housing, and jobs, as this study showed, although it wasn't enough to move ahead. Although most of the research on women migrants has focused on their survival circuits in global cities, this study indicates that these networks were active in rural areas too, as well as between rural and urban areas (for example, the recruitment agencies were located in cities, where the women originally landed, and they also phoned family contacts in London or Manchester). Rarely, however did carers make visits, leaving them to depend on one another for various forms of support. Making new friends, was difficult as most of the women were extremely busy, couldn't use their mobiles during work, and hurried from one task or home to the next. While they preferred to be busy, they often felt rushed and tired from running around. In addition, they were often pressured to work overtime, and to be on call for their companies when they needed them, in addition to dealing with constant changes with clients' care plans that diminished their own sense of control over their lives and sense of well-being. One woman said: 'I don't like this flexible work... I prefer start work and finish work and then have time for myself.'

For those carers who were nurses, this pressure was felt as normal, as most of them were used to working long hours in their previous jobs. But for other women, the hours were tiring and isolating. Since the people they spent the most amount of time with were clients, a number (although not all) of the carers resolved to relate well to the ones they liked most and even learn something from them (like, practicing their English, or learning about British history). They often projected familial attributes onto these clients, speaking of them as 'grandparents' and 'friends' and doing extra favours for them. These carers identified with these elderly clients that they cared for (almost all of them women), as not only marginalized in society, but also by their families who seemed too 'busy' to help them, and the carers often struggled to understand why these families didn't take care of them, as they would take care of their own parents if they could. The carers engaged in much emotional labour with the clients, and they were observed hugging and holding them when they were upset, apart from just dressing them, and they might listen to them for longer periods of time than their care plans specified. While the carers disclosed basic personal information to clients, company guidelines forbid them to reveal anything more about themselves so that the relationship remained 'professional.' Nonetheless, some of 
the carers felt attached to these older women and the intimacy that evolved from their interactions with one another. Also, nurturing care relationships takes much time and investment for it to work, on the parts of carers (Parrenas 2002), which is not counted or factored by employers whose focus is on the completion of care tasks.

The carers had little time for self-care activities; with one or two days off a week, they often slept in due to being tired from long on-call days. Yet they often called their families, sometimes every day (if they had children) to give emotional support and to connect with them. In these instances, the carers only revealed so much because they did not want to worry their families. When the carers had problems, they often turned to other carers in their company, rather than to employers or to their families abroad. One woman's car broke down and instead of contacting the employer, she phoned up her credit card company (in another country) and borrowed money. Then, she turned to her a colleague, and her visiting parents, who helped her to move the car. She then bought an older car from a client. A number of the carers, in wanting to acculturate, sought out information, when they could, about community resources, and attempted to mix with British-born residents as much as possible. Two sisters, for example, got involved with the local church. Another woman took her books to the local library and contributed to a Polish collection. Other carers shared houses with British residents and learnt about British culture from them. From their British-born colleagues, they learnt about tax issues. These contacts became part of their care networks and helped them to survive as new migrants.

3) The myth of English and vocational escalators for career advancement

Many carers were public sector workers before they arrived to England and experienced discrimination, not to mention being underemployed and not paid well. Subsequently they viewed these care positions, which paid them three to five times more money as contributing to their own, and their families', financial well-being, making economic incentives a primary motive for their migration. Yet, only a few carers identified these jobs as a 'career move' like the recruitment agencies had promoted them. The agencies appeared to specifically search for women who were ambitious, enthusiastic, and fit the bill. Those with advanced English language proficiencies were sought after, and they were given tests in English to document their levels for employers. The prospective carers were also interviewed by phone or in person in English to test their oral/aural skills. The concern, according to the employers, was the carers' abilities to be understood and follow instructions around the clients' needs. Yet, employers would often confuse proficiencies with accents, and this could lead to problems for some carers. Once they were hired, they were rarely fired because of their non-standard English accents. Instead, they were moved to other areas of a company where they would have less contact with clients, or they were not given additional responsibilities. This finding concurs with Norton's study (2000) of immigrant women in a Canadian workplace who were given jobs that would not require English or contact with Canadian citizens. Without practice, they became further marginalized, and lost confidence to speak. Power and position, rather than abilities, shaped their opportunities to advance. With their difficult hours, it 
was hard for carers to find advanced level English classes they could attend, and many couldn't try them, or dropped out.

In the Philippines, agencies often demanded educational qualifications of a certain caliber (tertiary education, nursing degrees and certificates) even though they were headed into caring jobs. Yet when they arrived, carers realized how far behind they were in terms of getting UK qualifications. Some of the carers adopted the policy discourse, and felt that their main barrier to advancing was to increase their English language skills even when they had used it in college. The carers also desired to increase whatever skills or qualifications they thought they needed. They sought information about tests, bought them from bookstores, borrowed them from friends and the library, studied for them, and easily passed their NVQs, even without knowing their value on the education market. Much of the studying was self-taught and through books and computers and these were important learning strategies. Nurses had many barriers for advancing their careers, including, needing high scores on language tests in order to start the adaptation process, association fees, the high costs of adaptation courses, and changing regulations and standards, and the knowledge that hospitals and care homes were not applying for work permits.

\section{CONCLUSION}

The women carers adapted to care industry demands through learning the hidden curriculum of the 'new work order' care force (as with the $4^{\text {th }}$ shift), and by forming 'justin-time' care networks (Louie 2001). These were critical supports, although not unproblematic adaptation mechanisms, because they involved great sacrifices and did not lead to career advancement. Although the carers were physically mobile, they experienced little upward mobility; the nurses in particular seemed to be deskilled, and entrapped. Other carers tried to re-skill so as to advance, only to experience barriers, including their initial entry into the care home (with debts, a contract they were afraid to break, and a managerial discourse of professionalism which didn't allow them freedom of expression). Additionally, the work organization (long on-call hours and low pay), prevented them from acquiring education that could genuinely move them forward. The NVQs held little value in the labour market compared to adaptation courses or higher education. In addition, there were few support services in Cumbria that reached out to the carers when they were discriminated against, or needed help, or counseling about negotiating new transnational identities - all of the mothers, for example, struggled with being faraway breadwinners and emotional comforters to their families. These women were indeed, a hidden, silenced group. Yet, they were central actors in the liberalisation and professionalisation of the care sector, smoothing the transition to privatised welfare. They allowed the elderly to become independent confidently, they reassured their families that their parents' treatment would be professional, they supplied a growing audit culture, they reduced costs for employers because they could use their networks to recruit, and needed little training, and they could be paid cut-rate salaries. Lastly, although unrecognized, these women were altering stagnant communities with their cultural diversity, economic drive, perceptive ingenuity, and educational and literacy capital. 


\section{REFERENCES}

Ackers, H.L. (2004) 'Citizenship, Migration and the Valuation of Care in the European Union', Journal of Ethnic and Migration Studies, 30(2), pp. 373-396.

Anderson, B. (2006). A very private business: migration and domestic work. Working paper no. 28. Centre on Migration, Policy, and Society (Compas). Oxford: University of Oxford.

Bennison, B. (2007). 'Heritage, creativity, and innovation - capturing the past or losing the future.' Paper given at Lancaster University, Regions and Regionalism conference, April 26, 2007.

Bolton, M. (2000). The third shift: Managing hard choices in our careers, homes and lives as women. San Francisco: Jossey-Bass.

Brinkmann, T. (2006). From green borders to paper walls: Jewish migrants from Eastern Europe in Germany before and after the Great War. Downloaded from the web on April 4, 2007: http://www.history.ac.uk/ihr/Focus/Migration/articles/brinkmann.html

Brilowski, G.A. \& Wendler, W.C. (2005). An evolutionary concept of caring. Journal of advanced nursing, 50, 641-650.

Brown, A., Kirpal, S. (2003), 'Old nurses with new qualifications are best': managers' attitudes towards the recruitment of health-care professionals in Estonia, France, Germany, Spain and the United Kingdom. In C. Warhurst, E. Keep, \& I. Grugulis (Eds), The Skills that Matter. New York: Palgrave.

Cox, R. (2006). The servant problem. London: IB Tauri

Datta, K., Mcllwaine, C. Evans, Y., Herbert, J., May, J. and Wills, J. (2006). Work, care and life among low-paid migrant workers in London: Towards a migrant ethic of care. London: Queen Mary, University of London.

Duffy, M. (2007). Doing the dirty work: Gender, race, and reproductive labor in historical perspective. Gender \& Society, 21, 313-336.

Ellery, S.(2006). Labour pains. Guardian Unlimited. August 23, 2006.

Guardian [no author]. Campaign gives voice to migrants. July 20, 2007 http://education.guardian.co.uk/tefl/story/0,2132789,00.html.

Green, A. Owen, D. \& Wilson, R. (2006). Changing patterns of employment by ethnic group and for migrant workers. Warwick: Institute for Employment Research.

Hochschild, A. (2002). The second shift. New York: Avon Books.

Jackson, N.S. (1991). Skills training in transition: Implications for women. s for women. In J. Gaskell \& A. McLaren (Eds.). Women and education (pp. 351-370). Calgary: Detselig.

Johnston, R., Trlin, A., Henderson, A. and North, N. (2006). Sustaining and creating migration chains among skilled immigrant groups: Chinese, Indians, and South Africans in New Zealand. Journal of Ethnic and Migration Studies, 32 (7): 12271250 .

Kofman, E. (2000). The invisibility of skilled female migrants and gender relations in studies of skilled migration in Europe. International Journal of Population Geography, 6, 45-59.

Kofman, E., Phizacklea, A., Raghuram, P. \&. Sales, R. (2000). Gender and International Migration in Europe: employment, welfare and politics, London: Routledge. 
Cuban, Before proofs, Ethnnography and Education, v3, 1, March 2008, 81-96

LSC (2006). Migrant workers and the labour market: Review of LSC research on labour market participation, skills and skills provision for migrant workers. Coventry: Learning and Skills Council.

Mahler, S.J. \& Pessar, P.R. (2006). Gender matters: Ethnographers bring gender from the periphery toward the core of migration studies. International Migration Review, 40 (1): 27-63.

Louie, C.H. M. (2001). Sweatshop Warriors: Immigrant Women Workers Take on the Global Factory. South End Press, Cambridge, Massachusetts.

Milligan, C. (2001). Geographies of care: space, place, and the voluntary sector. Aldershot: Ashgate, Ltd.

Mohanty, C.T. (1997). Feminism without Borders: Decolonizing theory, practicing solidarity. :Durham, North Carolina: Duke University Press.

Momsen, J. H. (Ed.) (1999). Gender, migration, and domestic service. London: Routledge.

Naples, N. (2003). Feminism and method. New York: Routledge

Norton, B. (2000). Identity and language learning: Gender, ethnicity and educational change. Harlow, England: Longman/Pearson Education.

Pai, H. (2004) A Ethnography of global labour migration. Feminist Review, 77: 129-136

Parrenas, R.S. (2001). Servants of Globalization: Women, migration, and domestic work. Stanford: Stanford University Press.

Pemberton, S. and Stevens, C. (2007). Supporting Migrant workers in the north west of England. MSIO Policy Report 3. October 2006. Liverpool: University of Liverpool.

Porter, M. \& Judd, E. (1999). Feminists doing development: A practical critique. London: Zed Books.

Raghuram, P. \& Kofman, E. (2004). Out of Asia: Skilling, reskilling, and deskilling of female migrants. Women Studies International Forum, 27: 95-100.

Rainbird H, Munro A, and. Senker P, (2004). 'Running faster to stay in the same place? The intended and unintended consequences of government policy on workplace learning in the UK', in A. Cumming, N. Bascia, A. Datnow, K. Leithwood, D. Livingstone, Kluwer, (eds) International Handbook of Educational Policy (885901), Hingham, MA., Kluwer Academic Publishers.

Roberts, C. et al. (2005). Embedded teaching and learning in adult literacy, numeracy, and ESOL. London: NRDC.

Roe, P. and Cuerdon, P. (2004). Executive summary: An economic assessment of Cumbria 2004. Kendal: Cumbria Economic Intelligence Partnership and Cumbria County Council.

Sassen, S. (1998). Globalization and its discontents. New York: New Press.

Sassen, S. (2002). Global cities and survival circuits. In B. Ehrenreich and A. Hochschild (Eds.), Global woman: Nannies, maids and sex workers in the new economy. New York: Henry Holt \& Co.

Silvey, R. (2004). Power, difference, and mobility: feminist advances in migration studies. Progress in Human Geography 28 (4), 490-506.

Simon, A., Owen, C., Moss, P., and Cameron, C. (2002). Mapping the Care Workforce: Supporting Joined Up Thinking Secondary analysis of the Labour Force Survey for childcare and social care work. Understanding Children's Social Care 5. London: Institute of Education. 
Smith, D.E. (2005). Institutional ethnography: A sociology for people. New York: Rowman \& Littlefield.

Spivak, Gayatri Chakravorty. 1992. Teaching for the times. The Journal of the Midwest Modern Language Association 25 (1): 3-22.

Strauss, A. \& Corbin, J. (Eds.) (1997). Grounded Theory in Practice. London: Sage Publications.

Stromquist, N.P. (2006). Women's rights to adult education as a means to citizenship. International Journal of Educational Development, 26, (2), 140-152

Twigg, J. (2000). Carework as a form of bodywork. Ageing and society, 20, 389-411.

Weston, B. (2006). Stepping forward: The main steps to embedding Skills for Life in health and social care-what, why, and how. London: UNISON.

Winkleman-Gleed, A. (2004). Migrant nurses. Oxford: Radcliffe Medical Press 